\title{
Host microsatellite alleles in malaria predisposition?
} Sonali Gaikwad ${ }^{1}$, Richa Ashma ${ }^{1}$, Nirbhay Kumar ${ }^{2}$, Rajni Trivedi ${ }^{1}$ and VK Kashyap*1

Address: ${ }^{1}$ Central Forensic Science Laboratory, National DNA Analysis Centre, 30 Gorachand Road, Kolkata-700014, West Bengal, India and ${ }^{2}$ Malaria Research Institute, Department of Molecular Microbiology and Immunology, John Hopkins Bloomberg School of Public Health, E5144, 15 N.Wolfe Street, Baltimore, MD 21205, USA

Email: Sonali Gaikwad - sonali_gaikwad@rediffmail.com; Richa Ashma - richa_ashma74@yahoo.com; Nirbhay Kumar -nkumar@jhsph.edu; Rajni Trivedi - trivedi_r@hotmail.com; VK Kashyap* - vkk2k@hotmail.com

* Corresponding author

Published: 10 October 2005

Malaria Journal 2005, 4:50 doi:10.1 I86/1475-2875-4-50

This article is available from: http://www.malariajournal.com/content/4/l/50

(C) 2005 Gaikwad et al; licensee BioMed Central Ltd.

This is an Open Access article distributed under the terms of the Creative Commons Attribution License (http://creativecommons.org/licenses/by/2.0), which permits unrestricted use, distribution, and reproduction in any medium, provided the original work is properly cited.
Received: 12 June 2005

Accepted: 10 October 2005

\begin{abstract}
Background: Malaria is a serious, sometimes fatal, disease caused by Plasmodium infection of human red blood cells. The host-parasite co-evolutionary processes are well understood by the association of coding variations such as G6PD, Duffy blood group receptor, HLA, and beta-globin gene variants with malaria resistance. The profound genetic diversity in host is attributed to polymorphic microsatellites loci. The microsatellite alleles in bacterial species are known to have aided their survival in fatal environmental conditions. The fascinating question is whether microsatellites are genomic cushion in the human genome to combat disease stress and has causeeffect relationships with infections.

Presentation of the hypothesis: It is hypothesized that repeat units or alleles of microsatellites $\mathrm{THO}$ and $\mathrm{D} 5 \mathrm{~S} 8 \mathrm{I} 8$, located in close proximity to beta-globin gene and immune regulatory region in human play a role in malaria predisposition. Association of alleles at aforesaid microsatellites with malaria infection was analysed. To overrule the false association in unrecognized population stratification, structure analysis and AMOVA were performed among the sampled groups.
\end{abstract}

Testing of hypothesis: Associations of microsatellite alleles with malaria infection were verified using recombination rate, Chi-square, and powerful likelihood tests. Further investigation of population genetic structure, and AMOVA was done to rule out the confounding effects of population stratification in interpretation of association studies.

Implication of the hypothesis: Lower recombination rate $(\theta)$ between microsatellites and genes implicated in host fitness; positive association between alleles - I3 (D5S8/8), 9 (THOI) and strong susceptibility to Plasmodium falciparum; and alleles- 2 (D5S8/8) and 6 (THOI) rendering resistance to human host were evident. The interesting fact emerging from the study was that while predisposition to malaria was a prehistoric attribute, among $\mathrm{THOI}$ alleles; evolution of resistant allele- 6 was a recent phenomenon, which could conceivably be driven by infection related selective forces. The host's microsatellite allelic associations with malaria infection were valid in the light of low genetic variance between sampled groups and no population stratification. 


\section{Background}

Infectious diseases influence or respond to levels of host genetic variation [1]. As a part of the co-evolutionary process, pathogens had also acquired factors for mitigation and longer survival in the host milieu [2]. Plasmodium parasite causes infection of human red blood corpuscles causing malaria. Of its four species, Plasmodium falciparum infection is the leading cause of mortality, but the changes in environment and human demography have altered the host-parasite interactions that have subsequently affected the disease spectrum [3]. Malaria provides the paradigm for a disease that has shaped the human genome through natural selection of protective genetic traits. Many molecular studies have documented the associations of human's coding gene polymorphisms such as the haemoglobin variants ( $\mathrm{Hb} \mathrm{E}, \mathrm{Hb} \mathrm{C}, \mathrm{Hb} \mathrm{S}, \alpha$ - and $\beta$-thalassaemia), G6PD, membrane receptor (Duffy protein), blood group proteins, HLA (HLA-B53, DRB1*1302) and other immune regulatory region with malaria resistance $[4,5]$. However, human DNA harbours enormous diversity, maintained by neutral polymorphisms such as microsatellites (STR), which are the recombination 'hotspots' owing to repetitive length sequences. It is known that microsatellites present within Opa genes of prokaryotic bacterial species, namely, Neisseria gonorrhoeae, Hemophilus influenzae aid their survival in fatal environmental conditions [6]. However, it would be fascinating to explore whether high allelic diversity of microsatellite regions in human genome are genomic cushions that has causeeffect relationship aiding species survival against environmental stresses including large number of infections. This paper conjecture is tested and verified at microsatellite loci namely D5S818 and TH01, present in close proximity to human genes implicated in resistance (reproductive fitness) to malaria.

\section{Methods}

Investigations began after the approval from our Institutional Review Committee and the written consent of patients or the parents of the patients. Blood samples were collected from the patients including clinically positive for $P$. falciparum $(n=105)$ and Plasmodium vivax $(n=67)$ infections. The sickle cell anaemic $(n=72$ represents 49 different families) and $\beta$-thalassaemic ( $n=150$ represents 100 different families) patients with no incidence of malarial infection were also sampled. In order to have an overall profile for resistance and susceptibility to malaria, normal healthy individuals $(n=174)$ with no personal history of Plasmodium infection and haemoglobin disorder were also studied. The sample collection was restricted to the eastern zone of India.

DNA was isolated from lymphocytes of collected blood specimens following organic extraction protocol [7]. Nested-PCR was used to detect the presence of malaria parasites based on its small subunit ribosomal RNA gene [8]. ARMS-PCR and PCR-RFLP methods were employed to diagnose and confirm the carriers of $\beta$-thalassaemia and sickle cell anaemia respectively $[9,10]$. A total fifteen microsatellite loci including TH01 and D5S818 were amplified following user's manual and reagents supplied with PowerPlex $16^{\circledR}$ System (Promega Corporation, Madison, USA). These were subsequently detected on 6\% Long Ranger $^{\circledR}$ acrylamide gel mounted on ABI 377 DNA Sequencer (Applied Biosystems, Foster City, CA). Genotypes were determined using Genescan ${ }^{\mathrm{TM}}$ (version 3.7) and PowerTyper $^{\mathrm{TM}}$ (version 3.7) software packages.

At first, an admixture model assuming correlated allele frequency between groups for inferring population structure implemented in structure program version 2.0 was employed using genotype data of 13 unlinked markers [11]. Analysis of molecular variance (AMOVA) was carried out on genotype data of unlinked markers between two groups using Arlequin [12]. The proposed hypothesis of this paper was tested by various statistical computations. Recombination rate $(\theta)$ as an index of linkage between two loci [13] was computed between the host's 5q31-33 immune regulatory region controlling $P$. falciparum infection level [14] and D5S818 microastellite locus; and between $\beta$-globin gene(11p15.5) and TH01 (11p15.5) microastellite locus. The region from $\beta$-globin gene to TH01 marker spans $3.83 \mathrm{cM}(1 \mathrm{Mb}=1.168 \mathrm{cM})$. Allele frequencies at each locus in different patients and healthy individuals were estimated by gene count. Likelihoodbased tests for allelic associations were performed using the established model [15]. Age of the microsatellite alleles was also calculated $[16,17]$.

\section{Results and discussion}

Microsatellite alleles play a significant role in adaptation of bacteria and perhaps higher organisms to their everchanging environments. On the downside, they have also been linked to human diseases, production of bile pigment bilirubin and neurotransmitters [6]. Genetic epidemiologists are interested in exploring whether the high allelic diversity in human host has association with large number of infections including malaria or it may be due to population stratification.

The evaluation of model-based clustering method showed no evidence of population substructure between sampled groups, which in turn has implication in detecting valid association between a putative candidate allele and malaria disease (Figure 1). Analysis of molecular variance (AMOVA) shows that most of the variance in the sampled population is attributable to within population group variation $(98.5 \%)$ of the variance and between population group variation is less than $1.5 \%$. The fixation index, $\mathrm{F}_{\mathrm{ST}}$ for the whole sample is only 0.0146. The computed 


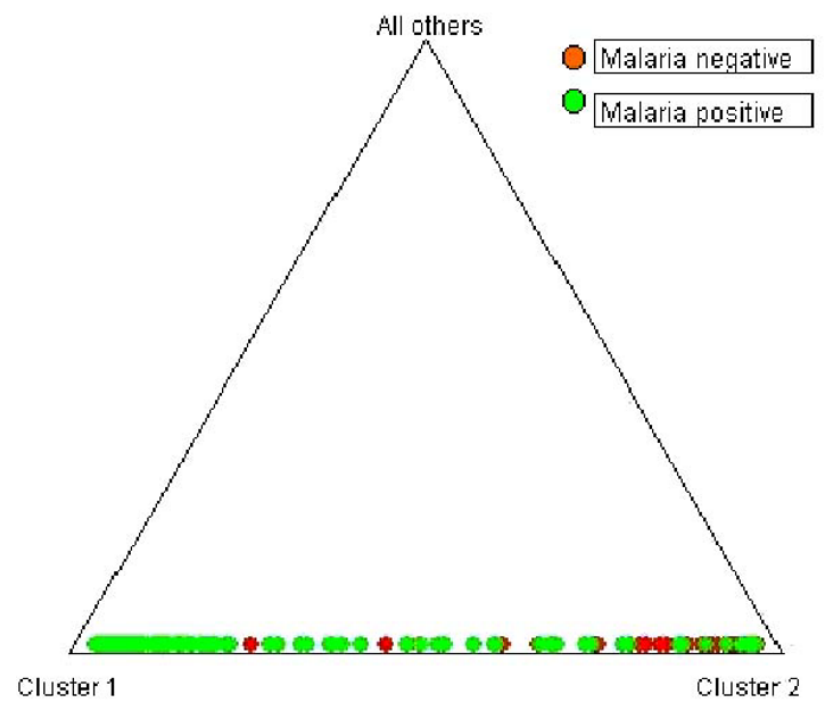

\section{Figure I}

Triangle plot showing estimates of membership coefficient (Q) for each individual by sampled groups, analysed under admixture model, assuming correlated allele frequencies.

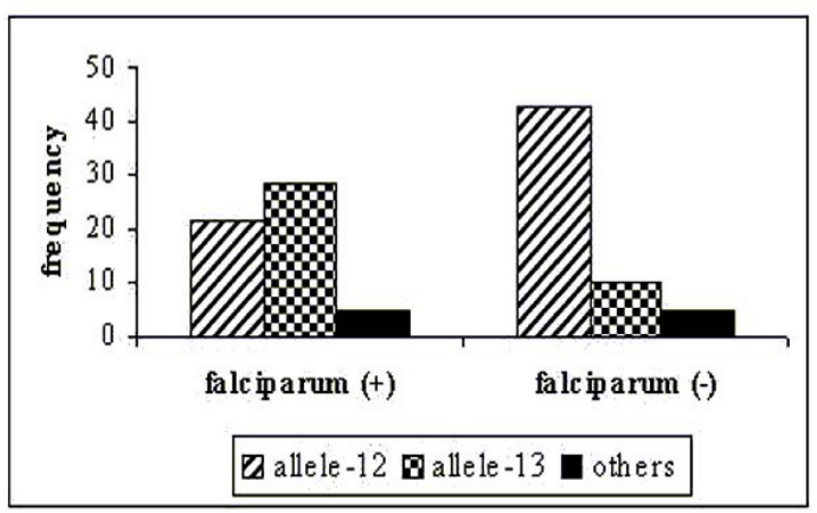

Figure 2

Distribution of allele - 12, 13 and others at microsatellite locus D5S8/8 in positive (+) and negative (-) samples of $P$. falciparum Malaria.

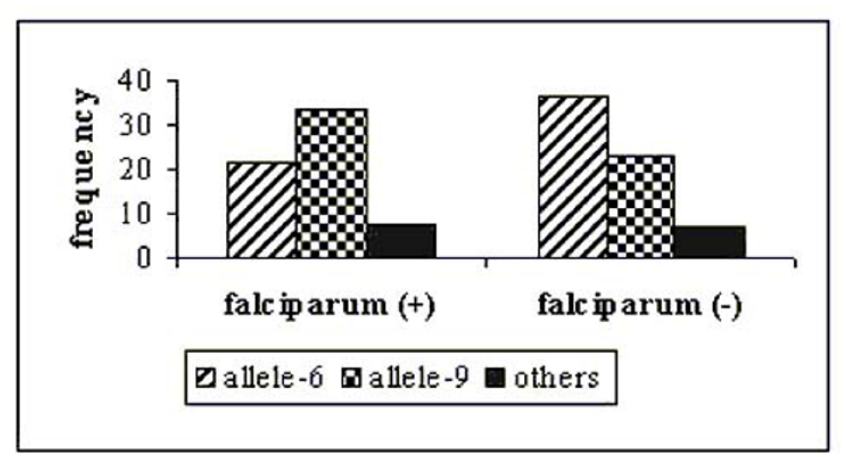

\section{Figure 3}

Distribution of allele $-6,9$ and others at microsatellite locus THOI in positive (+) and negative (-) samples of $P$. falciparum malaria.

recombination rate $(\theta)$ between host's $5 q 31-33$ and D5S818 equals 0.4 ; and between $\beta$-globin gene and THO1 was 0.06 . These values were lower than 0.5 (cut off) indicating linkage between studied microsatellite markers and genes owing to small genetic distance (cM) as compared to earlier reports $[18,19]$ that clearly depicted significant associations between widely separated loci (17-19 cM) on the same chromosome. The studied tetrameric microsatellite loci manifest varying frequencies of co-dominant alleles in global human populations. Although they are located within blocks of genes subject to selection, alleles numbering 7 to 16 at D5S818 and 4 to 9, 9.3, 10-11 and 13.3 at TH01 are considered selectively neutral. These alleles differentiated in frequency, age and evolutionary history because on arising they move through population either via genetic drift or being associated with positively selected marker, which may offers evolutionary benefits to the host. Allele frequencies at D5S818 locus in P. falciparum malaria patients and healthy individuals is presented in Figure 2, which showed the highest occurrence of allele-13 in P. falciparum patients and allele-12 in healthy individuals respectively. The distribution pattern in case of THO1 (Figure 3) showed allele-9 to be highly frequent in malaria positive isolates while allele- 6 was predominant in the normal group with no clinical history of malaria. The Chi-square $(\chi 2)$ test was applied to check the disproportionate distribution of alleles across two loci in patients and normal groups. Table 1 shows that the estimated values were significantly $(P<0.01)$ higher than the theoretical table value $(9.210)$, thereby indicating unequal and significant differences in microsatellite allele distribution (frequencies) between $P$. falciparum patients and controls indicate linkage disequilibrium between closely mapped locus and the disease locus. However, weak asso- 
Table I: Chi square and Likelihood estimates of alleles - 12, I3 at microsatellite D5S8 I 8; alleles - 6 and 9 at microsatellite TH0 I markers (Significance level $=1 \%$ ) and malaria susceptibility and resistance.

\begin{tabular}{|c|c|c|c|c|}
\hline \multirow[t]{3}{*}{ Malaria parasite } & \multicolumn{2}{|c|}{ Chi-Square values } & \multicolumn{2}{|c|}{ Likelihood-test estimates } \\
\hline & \multicolumn{4}{|c|}{ D5S818 } \\
\hline & Normal (allele-12) & Disease (allele-13) & $\begin{array}{c}\text { Associated with infection } \\
\text { (allele-13) }\end{array}$ & $\begin{array}{l}\text { Non-associated with } \\
\text { infection (allele-12) }\end{array}$ \\
\hline \multirow[t]{3}{*}{ P. falciparum } & 184.65 & 109.04 & 3.56 & $2.22 \times 10^{-4}$ \\
\hline & \multicolumn{4}{|c|}{ THOI } \\
\hline & Normal (allele-6) & Disease (allele-9) & $\begin{array}{c}\text { Associated with infection } \\
\text { (allele-9) }\end{array}$ & $\begin{array}{l}\text { Non-associated with } \\
\text { infection (allele-6) }\end{array}$ \\
\hline P. falciparum & 140.542 & 128.922 & 1.75 & $9.61 \times 10^{-2}$ \\
\hline
\end{tabular}

ciations between microsatellite alleles and $P$. vivax infection as well as haemoglobin variants (sickle cell anaemia and $\beta$-thalassaemia carriers) were observed. These results might be due to weak and mild malarial infection by $P$. vivax parasite and innate resistance to malaria by haemoglobin disorders. Therefore, the weakly associated samples were excluded from further analysis. Further, statistical analysis employed Likelihood-test, which considered microsatellite loci as bi-allelic markers (associated and non-associated alleles) that are represented in $2 \times 2$ contingency table. Here, an allele with the higher $\chi 2$ value than the table value (at $\mathrm{P}<0.01$ ) was taken to be associated. In $P$. falciparum infected group, the likelihood estimate of allele-13 at D5S818 was found to be significantly greater than allele-12 (see Table 1), and that of allele- 9 at locus TH01 was found to be greater than allele-6 (nonassociated allele with malaria) indicating a positive association of allele- 9 with the disease expression.

The prehistoric imprint of host susceptibility to malaria disease was demonstrated by allele-9 (THO1) and allele13 (D5S818) because these alleles are estimated to be older (age) than allele - 6 and allele-12. These findings further strengthen the role of host microsatellite alleles in malarial susceptibility as well as disease resistance since people with one version of the gene tend to be resistant to malaria while the other variant make the host susceptible. Furthermore, allele distribution patterns at locus TH01 in worldwide populations revealed high frequencies of allele- 6 than allele- 9 in European populations from Germany, Italy, and Slovakia [20], probably because of zero incidence of fatal falciparum malaria and negligible selection pressure. On the other hand, allele-9 in Indian populations [21] suggests primeval imprint of malaria susceptibility and genetic drift. Further, haemoglobin mutations evolved as presumed protective mechanisms against the infection.

\section{Conclusion}

A large number of STR loci dispersed in human genome led to postulation that they act as genomic cushion to combat stress of microbial infections. The study provided significant evidence that an individuals' genotype (microsatellite alleles) is a product of host interaction with $P$. falciparum infection. Thus, positive associations between allele-6 (TH01), allele-12 (D5S818) and malaria-negative (healthy) individuals demonstrate their role in genetic resistance whereas allele-9 (TH01) and allele-13 (D5S818) in P. falciparum infected individuals illustrate genetic predisposition towards the disease. Furthermore, predominance of allele-9 at TH01 (AATG repeat unit) in the individuals inhabiting malaria endemic area suggests genetic predisposition towards malaria as an archaic phenomenon. The host reproductive fitness has evolved during recent times in the form of resistant traits viz., haemoglobin variants (sickle cell mutation, $\beta$-thalassaemia) and allele- 6 (164 bp) at TH01 by deletion of $12 \mathrm{bp}$ from allele-9 (176 bp); both have significantly altered the parasite dynamics. The above findings are further supported by younger ages of microsatellite alleles associated with malaria resistance. A more recent discovery in a lowrisk malarial zone shows total absence of allele-9, predominance of lower repeat units at THO1 and lack of manifestation of malaria in Jarawa (an aboriginal tribal population of Andaman and Nicobar Island). However, the non-tribal inhabitants (migrants) of this island have higher incidence of malaria, thus substantiating further implication of allele- 9 in malaria susceptibility (Kashyap et al. unpublished data). The above findings are valid in the absence of population genetic structure.

\section{Authors' contributions}

VKK is the main investigator who has conceptualized the entire study. RA and SG performed the experiments, collated the data, performed statistical analysis and drafted 
the manuscript. NK and RT are the co-investigators who reviewed and improved the general presentation of this manuscript. All authors read and approved the final manuscript

\section{Acknowledgements}

We are thankful to the Bureau of Police Research and Development, Ministry of Home Affairs, Government of India, for financial support to carry out this research work. We also acknowledge all the blood donors and the co-operation of Drs. S.L Kate (Pune), R. Wankhede (Nagpur), R.K Nath, D.K Ganguly, B. Daripa, S.S.N Rao (Jamshedpur), D. GhoshDastidar and Ms. Neeta Sarkar (Kolkata) in the collection of blood. Ms. Seema Singh provided support in preparation of the manuscript.

\section{References}

I. Haldane JBS: The rate of mutation of human genes. Hereditas 1949, 35(suppl):267-273.

2. Hastings IM, Paget-McNicol S, Saul A: Can mutations and selection explain virulence in human $P$. falciparum infections? Malar 」 2004, 3:2.

3. Jobling MA, Hurles M, Tyler-Smith C: Health implications of our evolutionary heritage. In Human Evolutionary Genetics Origins, peoples and Disease New York: Garland Science, Taylor and Francis group; 2004:439-47I.

4. Mourant AE, Kopec AC, Domaniewska-Sobczak K: Blood groups and Diseases Oxford: Oxford University Press; 1978.

5. Hill AV: The immunogenetics of resistance to malaria. Proc Assoc Am Physicians 1999, I I I:272-277.

6. Moxon ER, Wills C: DNA microsatellites: agents of evolution? Sci Am 1999, 280:94-99.

7. Sambrook J, Fritsch EF, Maniatis T: Molecular cloning: a laboratorymanual 2 nd edition. Cold Spring Harbor: Cold Spring Harbor Laboratory Press; 1989.

8. Snounou G, Viriyakosol S, Zhu XP, Jarra W, Pinheiro L, Rosario VE, Thaithong S, Brown KN: High sensitivity of detection of human malaria parasites by the use of nested polymerase chain reaction. Mol Biochem Parasitol 1993, 6I:315-320.

9. Varawalla NY, Old JM, Sarkar R, Venkatesan R, Weatherall DJ: The spectrum of $\beta$ thalassemia mutations on the Indian subcontinent: the basis for prenatal diagnosis. Br J Haematol I99I, 78:242-247.

10. Kashyap VK, Ashma R: Microsatellite diversity in HbS carrier and normal individuals of tribal populations of malaria infested regions. Int Hum Genet 2003, 3:197-203.

II. Pritchard JK, Stephens M, Donnelly P: Inference of population structure using multilocus genotype data. Genetics 2000, I 55:945-959.

12. Schneider S, Roessli D, Excoffier L: Arlequin ver. 2.000 A software for population genetics data analysis. Genetics and Biometry Laboratory, University of Geneva, Switzerland; 2000.

13. Haldane JBS: The combination of linkage values and the calculation of distance between the loci of linked factors. J Genet 1919, 8:299-309.

14. Rihet P, Traore Y, Abel L, Aucan C, Traore-Leroux T, Fumoux F: Malaria in humans: Plasmodium falciparum blood infection levels are linked to chromosome 5q3I-q33. Am J Hum Genet 1998, 63:498-505.

15. Terwilliger JD: A powerful likelihood method for the analysis of linkage disequilibrium between trait loci and one or more polymorphic marker loci. Am J Hum Genet 1995, 56:777-787.

16. Kimura $M$, Ohta $T$ : The age of a neutral mutant persisting in a finite population. Genetics 1973, 75:199-2I2.

17. Slatkin M, Rannala B: Estimating allele age. Annu Rev Genomics Hum Genet 2000, I:225-249.

18. Payseur BA, Nachman MW: Microsatellite variation and recombination rate in the human genome. Genetics 2000, I 56: I 285-1298.

19. Zapata C, Rodriguez S, Visedo G, Sacristan F: Spectrum of nonrandomassociation between microstellite loci on human chromosome IIp | 5. Genetics 200I, I 58:|235-125I.

20. The distribution of human DNA-PCR polymorphisms [http:/ /www.uni- duesseldorf.de/]
21. Deka R, Shriver MD, Yu LM, Heidreich EM, Jin L, Zhong Y, McGarvey ST, Agrawal SS, Bunker CH, Miki T, Hundrieser J, Yin SJ, Raskin S, Barrantes R, Ferrell RE, Chakraborty R: Genetic variation at twentythree microsatellite loci in sixteen human population. J Genet 1999, 78:99-|2I.
Publish with Biomed Central and every scientist can read your work free of charge

"BioMed Central will be the most significant development for disseminating the results of biomedical research in our lifetime. " Sir Paul Nurse, Cancer Research UK

Your research papers will be:

- available free of charge to the entire biomedical community

- peer reviewed and published immediately upon acceptance

- cited in PubMed and archived on PubMed Central

- yours - you keep the copyright
BiolMedcentral 